\title{
Frequency domain control based on Quantitative Feedback Theory for vibration suppression in structures equipped with magnetorheological dampers
}

\author{
Mauricio Zapateiro, Hamid Reza Karimi, Ningsu Luo, Billie F. Spencer, Jr. *
}

August 1, 2008

\begin{abstract}
This paper addresses the problem of designing Quantitative Feedback Theory (QFT) based controllers for the vibration reduction in a structure equipped with an MR damper. In this way, the controller is designed in the frequency domain and the natural frequencies of the structure can be directly accounted for in the process. Though the QFT methodology was originally thought for linear time invariant systems, it can be extended to nonlinear systems. A new methodology is proposed for characterizing the nonlinear hysteretic behavior of the MR damper through the uncertainty template in the Nichols chart. The resulting controller is experimentally tested in real-time hybrid testing basis.
\end{abstract}

\section{Introduction}

The protection of civil engineering structures has always been a major concern especially when these structures are built in places prone to hazardous weather conditions (e.g. hurricanes, tsunamis) or in zones of intense seismic activity or when the structure is subjected to heavy loadings (e.g. heavy traffic on a bridge). If a structure is not well protected against these phenomena, they can suffer severe damage, and as a consequence, produce personal injuries or death as could be seen during the earthquakes in Mexico City (1985), Kobe (1995), northwestern Turkey (1999), those that struck southern Asia in 2004 followed by the tsunamis or more recently in China (2008).

To make structures more resistant against these phenomena, passive and active dampers were initially proposed. Passive dampers alleviate the energy dissipation of

*Mauricio Zapateiro, Hamid Reza Karimi and Ningsu Luo are with the Institute of Informatics and Applications, University of Girona, Girona, Spain. E-mails: \{mauricio.zapateiro, hamidreza.karimi, ningsu.luo\}@udg.edu. Billie F. Spencer Jr. is with the Department of Civil and Environmental Engineering, University of Illinois at Urbana - Champaign, USA. E-mail: bfs@uiuc.edu Key words and phrases: magnetorheological damper, smart structures, vibration reduction, semiactive control 
the main structure by absorbing part of the input energy, without the need of external power sources. However, these are not adaptable to different loading conditions (Yoshioka et al. 2002)). Active dampers, on the other hand, are adaptable but require large power sources and additional hardware like sensors and DSP's to operate. Active dampers can also inject energy to the structure and may destabilize it in a bounded-input bounded-output sense(Spencer \& Sain 1997).

The disadvantages of passive and active dampers have led the search to another solution: semiactive devices which are particularly promising in addressing a number of these problems (Dyke et al. 1998). Semiactive devices combine the features of active and passive devices: their properties can be adapted in real time but they cannot inject energy to the system. Semiactive devices have shown to perform significantly better than passive devices and as well as active devices without requiring large power sources, thus allowing for battery operation (Spencer \& Song. 1999)).

MR fluid dampers are one the most attractive semiactive devices. Compared to others, MR dampers can generate a high yield strength, have low costs of production, require low power, and have a fast response and small size. MR dampers however, are characterized by a complex nonlinear dynamics which makes mathematical treatment challenging. Several models and control techniques have been developed but none of them is definite. Thus, MR damper implementation for vibration mitigation purposes adds another problem to the control design.

In the case of systems with MR dampers, a number of control techniques have been developed. The clipped optimal control (Dyke et al. 1996) was one of the first controllers developed for this class of systems. An optimal controller is designed to estimate the force that mitigates the vibrations in the structure. However, the MR damper dynamics are ignored and the control signal takes on two values only, chosen according to an algorithm.

The control based on Lyapunov's stability theory, has been approached and successfully been tested in structures such as buildings, bridges and car suspension systems (Jansen \& Dyke 2000), (Yang 2001), (Wang \& Gordaninejad 2002), (Luo et al. 2003), (Park \& Jeon 2002) and (Nagarajaiah et al. 2006)). The control objective is to choose the control inputs so as to make a Lyapunov function derivative as negative as possible. There is not a unique function satisfying these characteristics so this results in a variety of control laws.

Other control methods have been proposed such as bang-bang control (McClamroch et al. 1994, McClamroch \& Gavin 1995), (Jansen \& Dyke 2000); sliding mode control (Luo et al. 2003), (Villamizar et al. 2003) and (Moon et al. 2003); backstepping control (Luo et al. 2007), (Villamizar 2005) and (Zapateiro, Villamizar \& Luo 2008); and intelligent control such as fuzzy logic and neuro fuzzy control (Kim \& Roschke 2006) and (Schurter \& Roschke 2001).

Most of these semiactive structural control strategies are based on the idea of attenuating vibrations or maintaining them within certain acceptable ranges, when external 
forces such as earthquakes or strong winds act on the structures. The controller design is done usually by considering that the structural model and its associated parameters are known or uncertain but bounded. The effectiveness of control system depends on the precision of estimated or measured variables (displacement, velocities, etc). However, the behavior of controlled structures depends not only on the magnitude of the external excitation but also on its frequency modes so the modal frequency control is of a big interest for achieving the safety and comfort of the structures.

Luo et al. (n.d.) proposed the application of the Quantitative Feedabck Theory (QFT) control to design a semiactive controller in the frequency domain in structures with MR dampers. Numerical simulations and experiments on small scale specimens showed the feasibility of applying quantitative feedback control in larger systems. In these works, however, an algorithm similar to the clipped optimal control was followed, i.e. the nonlinear dynamics of the MR damper were ignored. A step further was done by Zapateiro, Karimi \& Luo (2008) by proposing the inclusion of the MR dynamics in the QFT control design. Feasibility of this approach was proved by numerical simulations. In this paper, a QFT controller that includes the MR damper dynamics is proposed as an extension of the previous works. The design is experimentally evaluated in a real-time hybrid testing basis to analyze the performance in large-scale structures.

This paper is organized as follows. Section 2 explains the basic concepts about quantitative feedback control. Section 3 describes the experimental environment and the structure model that will be used for control design. Section 4 presents the details of the QFT controller formulation for the experimental structure. Section 5 presents the experimental results and the controller performance analysis. Finally, the conclusions are oultined in Section 6.

\section{Quantitative Feedback Theory}

QFT is a frequency control methodology based on the notion that feedback is only necessary when there is uncertainty and nonmeasurable disturbances actuating on the plant. The basic developments with QFT are focused on the control design problem for uncertain Linear Time Invariant (LTI) Systems, as shown in Figure 1. In this figure, $\mathbf{R}$ represents the command input set, $\mathbf{P}$ the plant set and $\mathbf{T}$ the transfer function set. For each $R(s) \in \mathbf{R}, P(s) \in \mathbf{P}$, the closed loop output will be $Y(s)=T(S) R(s)$ for some $T(s) \in \mathbf{T}$. For a large class of such problems, QFT is executable, i.e., a pair of controller $F(s)$ and $G(s)$ can be found to guarantee that $Y(s)=T(S) R(s)$. Suppose that the plant $P(s)$ is an uncertain but known member of the set $\mathbf{P}$. The designer is free to choose the prefilter $F(s)$ and the compensator $G(s)$ in order to ensure that the system transfer function $T(s)=F(s) P(s) G(s) /(1+P(s) G(s))$ satisfies that assigned specifications.

The uncertain plant model $P(s)$ and its frequency and time domain specifications are represented in the Nichols chart through the use of the Borowitz-Sidi bounds. These bounds determine the regions where the nominal open loop transfer function $L_{0}(s)=$ $G(s) P_{0}(s)$ may lie so that all the design specifications can be achieved. 


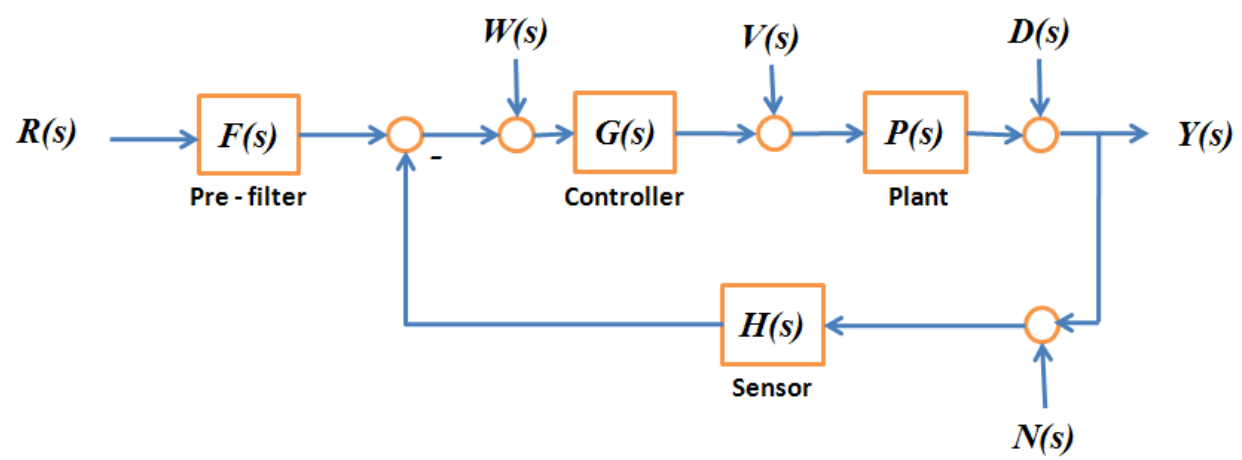

Figure 1: Schematic of the QFT control system.

The QFT methodology design can be summarized as follows Houpis et al. (2005):

1. Plant model, template generation and nominal plant election. The plant is represented in the Laplace domain; each uncertain parameter is assigned a range of variation and the frequencies of interest are chosen within the expected operation range. At each frequency of interest and for each possible value of the uncertain parameters, the plant model $P(j \omega)$ becomes a complex number that can be represented in the Nichols chart $(\mathrm{dB}, \Phi)$. This set of complex numbers is called the templates. One of these plants is chosen as the nominal plant.

2. Design specifications. The inputs to the system of system of Figure 1 are $R(s)$ (the reference), $W(s), D_{1}(s)$ and $D_{2}(s)$ (the disturbances) and $N(s)$ (the noise). $Y(s)$ is the variable to be controlled, $E(s)$ is the error and $U(s)$ is the control signal. The following following transfer functions can be obtained:

$$
\begin{gathered}
Y=\frac{1}{1+P G H} D_{2}+\frac{P}{1+P G H} D_{1}+\frac{P G}{1+P G H}(W+F R)-\frac{P G H}{1+P G H} N \\
U=\frac{G}{1+P G H}(W+F R)-\frac{G H}{1+P G H}\left(N+D-2+D_{1}\right) \\
E=-\frac{H}{1+P G H} D_{2}+\frac{P H}{1+P G H} D_{1}+\frac{P G H}{1+P G H} W+\frac{1}{1+P G H} F R-\frac{H}{1+P G H} N
\end{gathered}
$$

By limiting the transfer function magnitudes of Eqns. 1 - 3, it is possible to set the stability and robustness specifications such as disturbance rejection, tracking and noise rejection.

3. Bound generation. Once chosen the nominal plant, the next step is to represent the closed loop and uncertainty plant specifications in a set of restriction curves 
or bounds as known as Horowitz-Sidi bounds for each frequency of interest on the Nichols chart. This information synthesis allows the design of the controller using only the nominal plant. For each frequency and for each design specification there is one bound. When all these bounds are calculated, then the most restrictive one per frequency is kept.

4. Loop shaping. When the most restrictive bounds are found, the controller is synthesized by adding a gain, poles and zeros such that the loop function $L_{0}(j \omega)$ lies in the Nichols chart in the regions where the design specifications can be achieved. The optimal controller is the one that having the minimum gain, lies on the bounds a each frequency of interest. In this case, it is possible to affirm that the controller accomplishes all the design specifications.

5. Prefilter. When tracking specifications are required, the prefilter $F(s)$ must be designed. The prefilter synthesis is similar to that of the controller.

6. Design validation. This step involves the performance evaluation of the controller and its adjustment until all the design specifications are satisfied within acceptable limits.

Most of the design process can be done with the help of software packages such as the QFT toolbox for Matlab. The loop shaping process is left to the ability and experience of the designer.

\section{$3 \quad$ Experimental setup}

This section describes the experimental environment where the controller will be tested. Experiments are executed in a real-time hybrid testing (RTHT) configuration available at the Smart Structures Laboratory, University of Illinois Urbana - Champaign (USA), as shown in Figure 2. It consists of a computer that simulates the structure to be controlled and generates the commanding signals (desired displacement and control signals); a small-scale MR damper that is driven by a hydraulic actuator which in turn is controlled by a servo-hydraulic controller; and DSP, A/D and D/A hardware for signal processing. Sensors available include a linear variable displacement transformer (LVDT) for displacement measurements and a load cell to measure the MR damper force. A fully detailed description of this real-time hybrid testing implementation can be found in Carrion \& Spencer (2007).

\subsection{Structure model}

The schematic of the 3-story building to be controlled is shown in Figure 3. The building can be modeled with the second order motion equation:

$$
\mathbf{M}_{\mathbf{s}} \ddot{\mathbf{x}}+\mathbf{C}_{\mathbf{s}} \dot{\mathbf{x}}+\mathbf{K}_{\mathbf{s}} \mathbf{x}=G_{s} f-\mathbf{M}_{\mathbf{s}} L_{s} \ddot{x_{g}}
$$




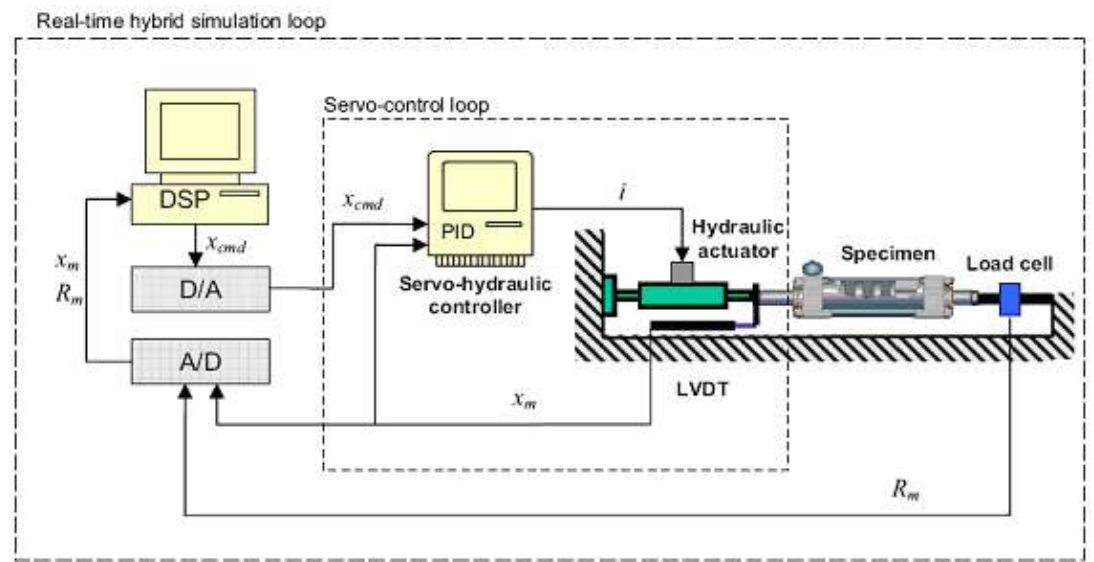

Figure 2: RTHT system schematic.

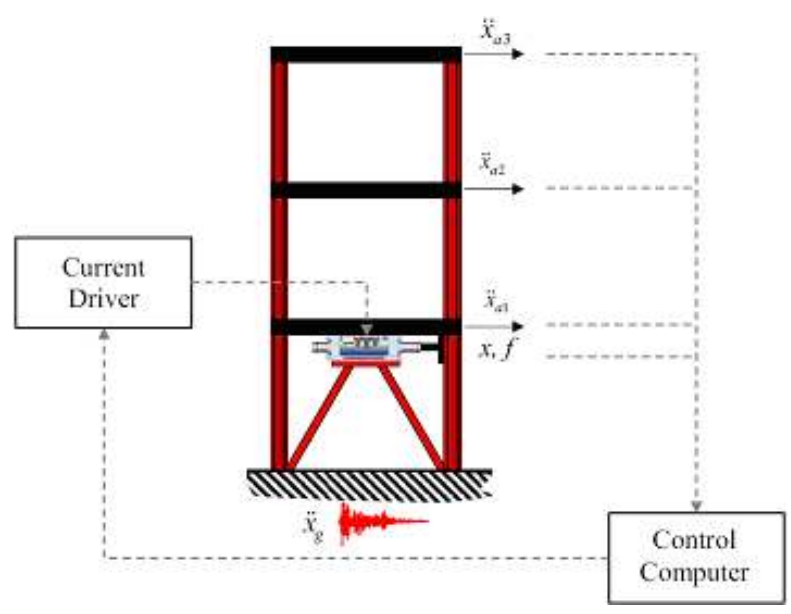

Figure 3: Schematic of the 3-story building with MR damper.

where the matrices and vectors $\mathbf{M}_{\mathbf{s}}, \mathbf{C}_{\mathbf{s}}, \mathbf{K}_{\mathbf{s}}, G_{s}$ and $L_{s}$ are given by:

$$
\begin{gathered}
\mathbf{M}_{\mathbf{s}}=\left[\begin{array}{ccc}
m_{1} & 0 & 0 \\
0 & m_{2} & 0 \\
0 & 0 & m_{3}
\end{array}\right]=\left[\begin{array}{ccc}
20253 & 0 & 0 \\
0 & 20253 & 0 \\
0 & 0 & 20253
\end{array}\right] k g \\
\mathbf{C}_{\mathbf{s}}=\left[\begin{array}{ccc}
c_{11} & -c_{12} & 0 \\
-c_{21} & c_{22} & -c_{23} \\
0 & -c_{32} & c_{33}
\end{array}\right]=\left[\begin{array}{ccc}
7243.2 & -2070 & 0 \\
-2070 & 4138.2 & -2070 \\
0 & -2070 & 2070
\end{array}\right] N-s / m \\
\mathbf{K}_{\mathbf{s}}=\left[\begin{array}{ccc}
k_{11} & -k_{12} & 0 \\
-k_{21} & k_{22} & -k_{23} \\
0 & -k_{32} & k_{33}
\end{array}\right]=\left[\begin{array}{ccc}
9932 & -5661 & 0 \\
-5661 & 11338 & -5661 \\
0 & -5661 & 5661
\end{array}\right] N / m \\
G_{s}=[-1,0,0]^{T} L_{s}=[1,1,1]^{T}
\end{gathered}
$$


$f$ is the MR damper force and $\ddot{x}_{g}$ is the incoming earthquake acceleration. The natural frequencies and the damping ratios of the structure corresponding to the first, second and third mode are $1.09 \mathrm{~Hz}(0.31 \%), 3.17 \mathrm{~Hz}(0.62 \%)$ and $4.74 \mathrm{~Hz}(0.63 \%)$ respectively.

\subsection{MR damper}

The MR damper used in the experiments is the RD-1005 manufactured by the Lord Corporation (www.lord.com), shown in Figure 4. The damper is $216 \mathrm{~mm}$ long in its extended position, is $38.1 \mathrm{~mm}$ in diameter and has a stroke of $25.4 \mathrm{~mm}$. It contains $50 \mathrm{ml}$ of MR fluid and can generate forces up to $3000 \mathrm{~N}$ approximately. The magnetic field is generated by the current from a PWM amplifier (the RD-1002 Wonder Box, from Lord Corp.).

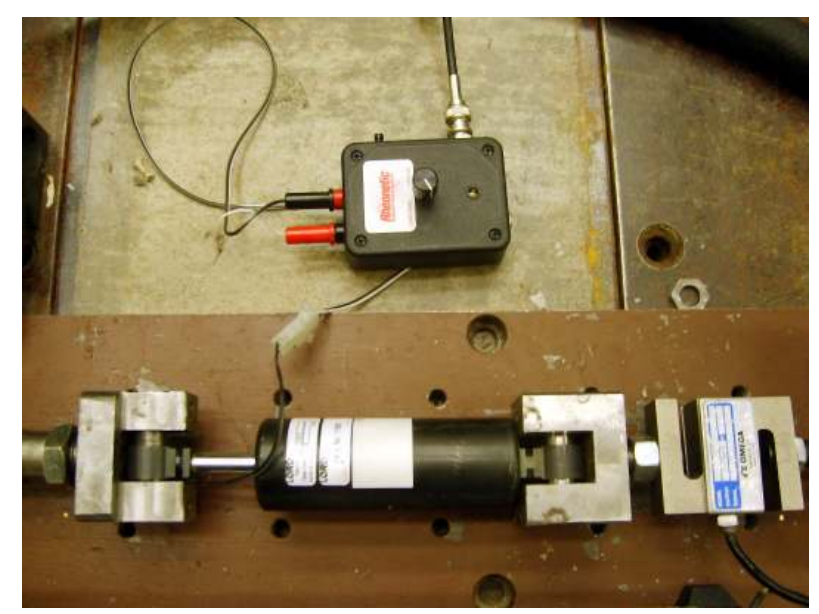

Figure 4: MR damper and PWM system.

The dynamics of the damper can be modeled by the Bouc-Wen model (Spencer et al. 1997), as shown in Eqs. 9 - 10:

$$
\begin{aligned}
& f_{m r}=\left(c_{0 a}+c_{0 b} u\right) \dot{x}_{1 r}+\left(k_{0 a}+k_{0 b} u\right) x_{1 r}+\left(\alpha_{a}+\alpha_{b} u\right) z \\
& \dot{z}=-\gamma|\dot{y}| z|z|^{n-1}-\beta \dot{y}|z|^{n}+A \dot{y}
\end{aligned}
$$

$u$ is the output of the first order filter introduced to model the dynamics of the MR damper:

$$
\dot{u}=-\eta(u-v)
$$

The parameters of the MR damper specimen are: $\alpha_{a}=33.27 \mathrm{~N} / \mathrm{m}, \alpha_{b}=182.65 \mathrm{~N} / \mathrm{m}-$ $V, c_{0 a}=754.41 \mathrm{~N}-\mathrm{s} / \mathrm{m}, c_{0 b}=712.73 \mathrm{~N}-\mathrm{s} / \mathrm{m}-\mathrm{V}, k_{0 a}=1137.57 \mathrm{~N} / \mathrm{m}, k_{0 b}=$ $1443.50 N / m-V, x_{0}=0 m, \gamma=4209.8 m^{-2}, \beta=4205.2 m^{-2}, A=10246, n=2$, 
$\eta=57 s^{-1}$. The following scaling factors are used to integrate the physical small-scale MR damper to the numerical large-scale structure: the first floor relative displacement is reduced by a factor $S_{L}=7.25$ to obtain the damper piston displacement and the MR damper force is increased by a factor $S_{F}=60$ to obtain the input force to the structure.

Figures 5 and 6 show a comparison between the experimental dynamics of the MR damper and those predicted by the Bouc-Wen model. In the first case, the damper is subject to a sinusoidal displacement at $5 \mathrm{~Hz}$ and $0.254 \mathrm{~cm}$ amplitude. The voltage periodically switches from $0 \mathrm{~V}$ to $5 \mathrm{~V}$. In the second case, the damper is subject to random displacement and random voltage excitation.
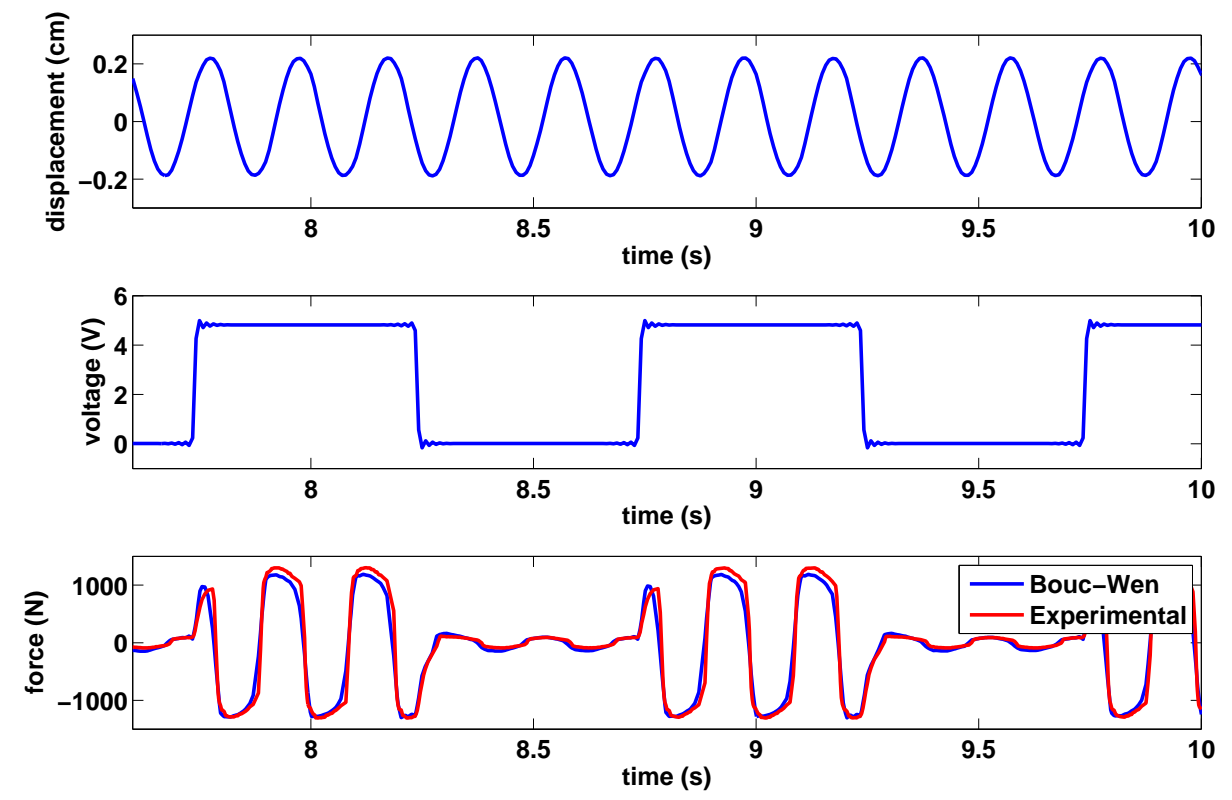

Figure 5: MR damper dynamics: Sinusoidal displacement and switching voltage.

\subsection{Hydraulic actuator dynamics}

The MR damper is driven by a hydraulic actuator which receives a commanding signal from the computer where the simulation runs to impose a displacement to it. A block diagram that shows the interaction between the numerical model and the dynamic system is illustrated in Figure 7.

The entire physical system can be modeled by a transfer function $G_{x u}(s)$ whose input $u$ is the commanded displacement and the output $x$ is the piston displacement. Modeling the dynamic systems is useful for simulating the RTHT experiments. The transfer function $G_{x u}(s)$ varies according to the MR damper input voltage. Two cases are identified corresponding to the damper operating at $V_{0}=0 \mathrm{~V}$ and $V_{\max }=5 \mathrm{~V}$ respectively. 

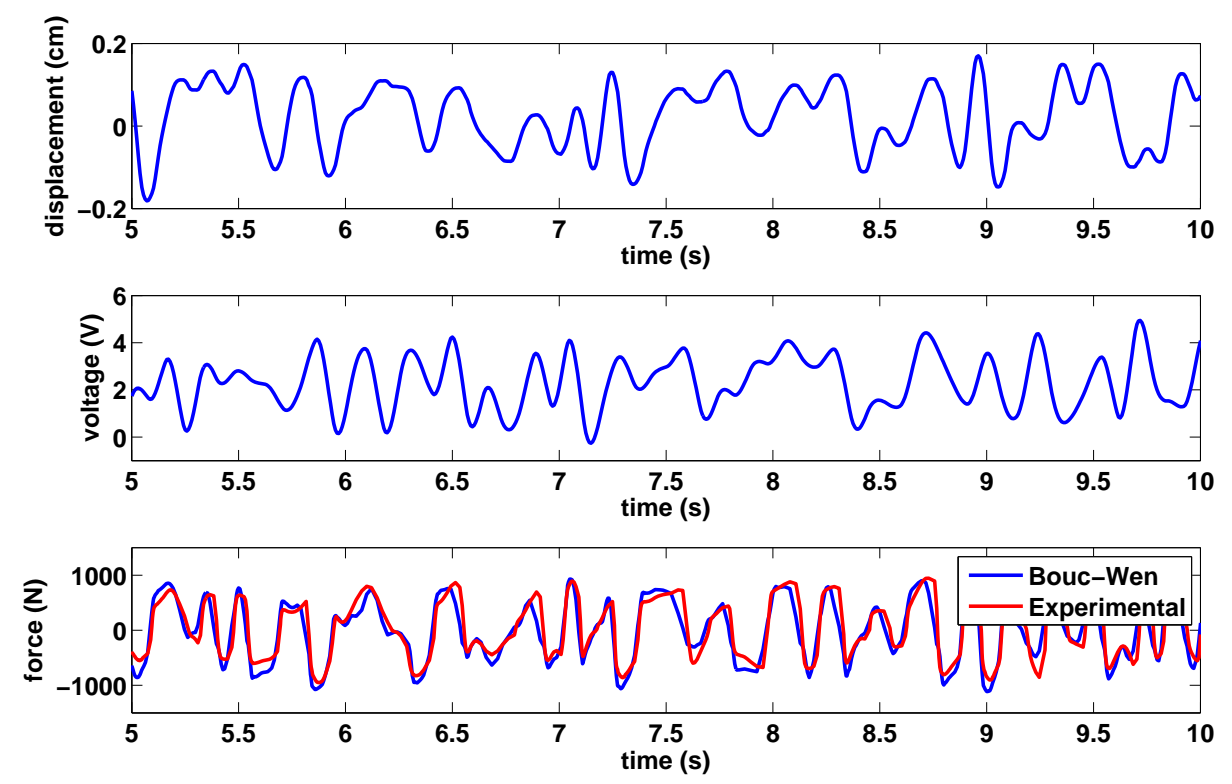

Figure 6: MR damper dynamics: random displacement and voltage.

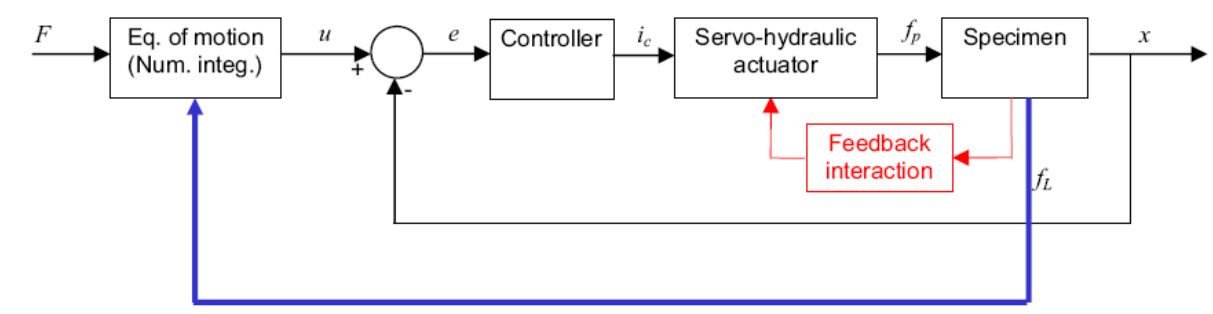

Figure 7: Numerical model and physical system interaction. 
An algorithm was designed by Carrion \& Spencer (2007) to provide a smooth transition from $G_{x u, V_{0}}(s)$ to $G_{x u, V_{\max }}(s)$ and vice versa when the damper voltage varies during the experiments. A block diagram of this algorithm is shown in Figure 8. The model equations are:

$$
\begin{aligned}
& X(s)=X_{a}(s)+X_{b}(s) W(s) \\
& X_{a}(s)=G_{a}(s) U(s)=G_{x u, V_{0}}(s) U(s) \\
& X_{b}(s)=G_{b}(s) U(s)=\left(G_{x u, V_{\max }}(s)-G_{x u, V_{0}}(s)\right) U(s) \\
& W(s)=G_{t}(s) V(s)
\end{aligned}
$$

The transfer functions are given by:

$$
\begin{aligned}
& G_{x u, V_{0}}(s)=\frac{6118670}{(s+161.5)\left(s^{2}+222.2 s+3.79 \times 10^{4}\right)} \\
& G_{x u, V_{\text {max }}}(s)=\frac{4056971}{(s+106.1)\left(s^{2}+221 s+3.82 \times 10^{4}\right)} \\
& G_{t}(s)=\frac{1 / 5}{0.0048 s+1}
\end{aligned}
$$

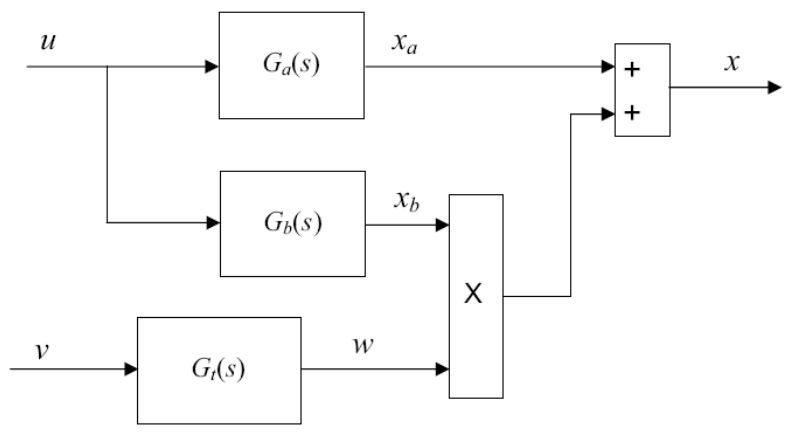

Figure 8: Actuator dynamics with bumpless transfer.

Due to the inherent dynamics of the physical system (e.g. time delays), a feedforward controller $G_{f f}(s)$ is added to the system for compensation purposes. In this way, the commanded displacement ( $u$, input to the physical system) is calculated based on the desired displacement ( $d$, output from the simulations) and the inverse dynamics of the physical system. As a result, $x \approx d$. A schematic of the compensated system is shown in Figure 9 .

A similar approach to that of Figure 8 is followed to provide a smooth transition between both compensators. The algorithm is shown in Figure 10. The model equations are: 


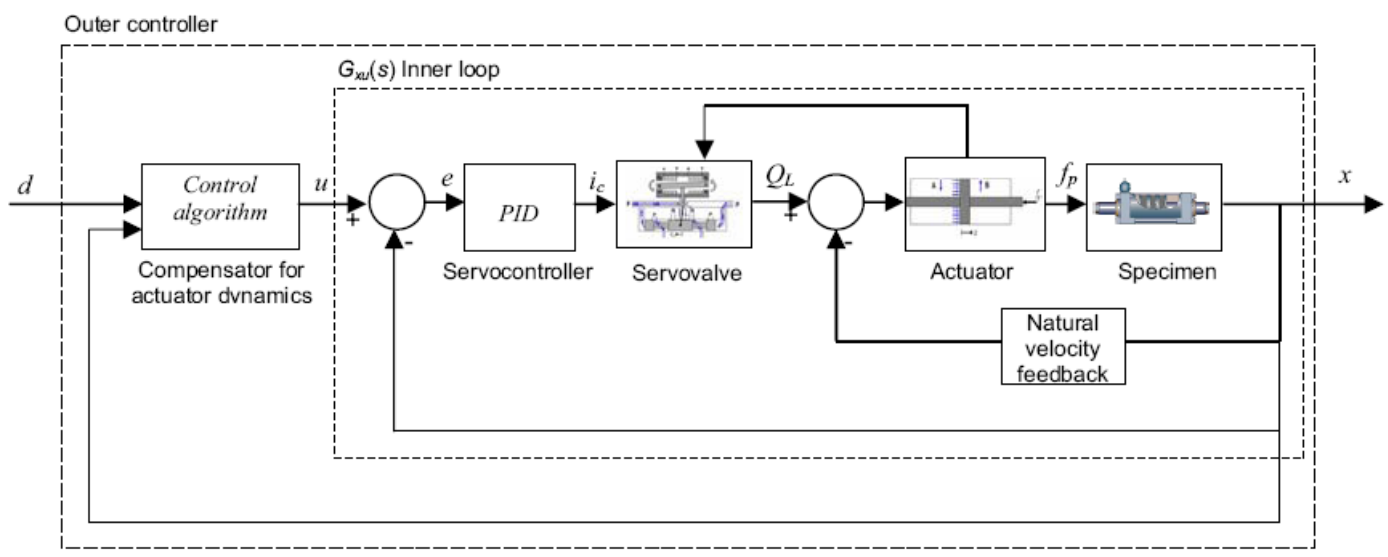

Figure 9: Diagram of the complete system with dynamics compensation.

$$
\begin{aligned}
& U_{f f}(s)=U_{a}(s)+U_{b}(s) W(s) \\
& U_{a}(s)=G_{f f, a}(s) D(s)=G_{f f, V_{0}}(s) D(s) \\
& U_{b}(s)=G_{f f, b}(s) D(s)=\left(G_{f f, V_{\max }}(s)-G_{f f, V_{0}}(s)\right) D(s) \\
& W(s)=G_{t}(s) V(s)
\end{aligned}
$$

The transfer functions are given by:

$$
\begin{aligned}
& G_{f f, V_{0}}(s)=\frac{3375(s+161.5)\left(s^{2}+222.2 s+3.79 \times 10^{4}\right)}{(s+2422)\left(s^{2}+3333 s+8.527 \times 10^{6}\right)} \\
& G_{f f, V_{\text {max }}}=\frac{3375(s+106.1)\left(s^{2}+221 s+3.82 \times 10^{4}\right)}{(s+1590)\left(s^{2}+3315 s+8.595 \times 10^{6}\right)} \\
& G_{t}(s)=\frac{1 / 5}{0.0048 s+1}
\end{aligned}
$$

Figure 11 shows a comparison between the desired, the commanded and the measured piston displacement during the execution of an experiment. The lower figure is a close-up of the upper one.

\section{QFT controller formulation}

To begin with the design of the QFT controller, the structure model of Eq. 4 is rewritten in the following state space form:

$$
\begin{aligned}
& \dot{\mathbf{z}}=\mathbf{A z}+\mathbf{B} f+\mathbf{E} \ddot{x}_{g} \\
& \mathbf{y}=\mathbf{C} \mathbf{z}+\mathbf{D} f+\mathbf{v}
\end{aligned}
$$




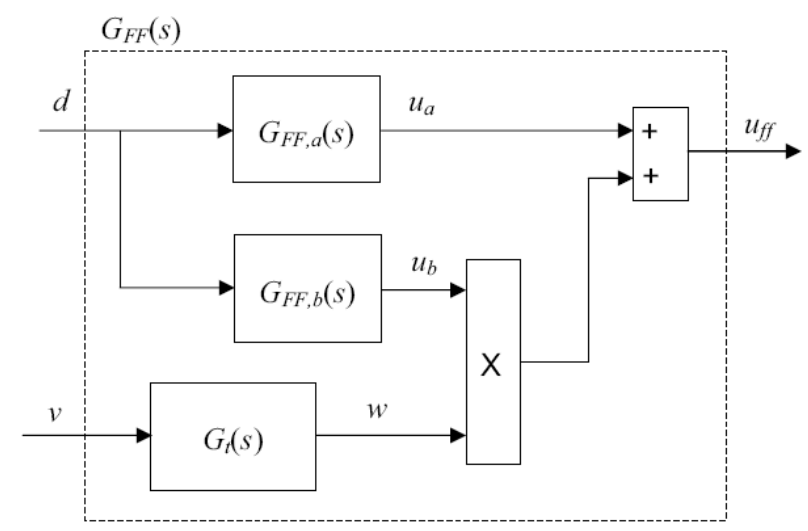

Figure 10: Compensator dynamics with bumpless transfer.

where $\mathbf{z}=[\mathbf{x}, \dot{\mathbf{x}}]^{T}$ is the state vector, $\mathbf{y}=\left[\ddot{\mathbf{x}}_{\mathbf{a}}, x_{1 r}\right]$ is the output vector which contains the measurements of the absolute accelerations of each floor and the relative displacement of the first floor and $\mathbf{v}$ accounts for the measurement noise. The matrices $\mathbf{A}, \mathbf{B}, \mathbf{C}, \mathbf{D}$ and $\mathbf{E}$ are given by:

$$
\begin{aligned}
& \mathbf{A}=\left[\begin{array}{cc}
0 & \mathbf{I} \\
-\mathbf{M}_{\mathbf{s}}^{-1} \mathbf{K}_{\mathrm{s}} & -\mathbf{M}_{\mathbf{s}}^{-1} \mathbf{C}_{\mathrm{s}}
\end{array}\right] \quad \mathbf{B}=\left[\begin{array}{c}
\mathbf{0} \\
-\mathbf{M}_{\mathbf{s}}^{-1} \mathbf{G}_{\mathbf{s}}
\end{array}\right] \quad \mathbf{E}=\left[\begin{array}{c}
0 \\
-\mathbf{L}_{\mathbf{s}}
\end{array}\right]
\end{aligned}
$$

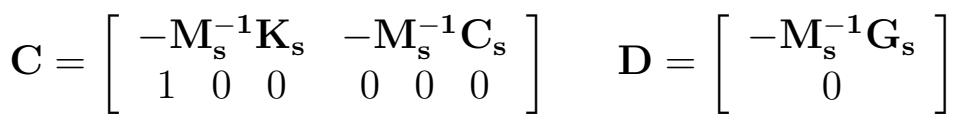

The building model is now divided into two subsystems accounting for the first floor dynamics, where the MR damper is attached, and the rest of the structure that accounts for the dynamics of all the floors above the base. Thus, the building can be modeled by the following set of equations:

$$
\begin{gathered}
S_{m}: \mathbf{M}_{\mathbf{s} 2} \ddot{\mathbf{x}}_{\mathbf{a}}+\mathbf{C}_{\mathbf{2 a}} \dot{\mathbf{x}}_{\mathbf{a}}+\mathbf{K}_{\mathbf{s} \mathbf{2}} \mathbf{x}_{\mathbf{a}}=\mathbf{B}_{\mathbf{s} \mathbf{2}} \mathbf{x}_{\mathbf{1 a}}+F_{g} \\
S_{b}: m_{1} \ddot{x}_{1 a}+c_{11} \dot{x}_{1 a}+k_{11} x_{1 a}=-f_{m r}-f_{c}+f_{g}
\end{gathered}
$$

where $S_{m}$ stands for the main structure subsystem and $S_{b}$ is the base subsystem. The $a$ sub-index means absolute coordinates. The matrices $\mathbf{M}_{\mathbf{s} 2}, \mathbf{C}_{\mathbf{s} 2}, \mathbf{K}_{\mathbf{s} 2}$ and $\mathbf{B}_{\mathrm{s} \mathbf{2}}$ are given by:

$$
\begin{array}{lc}
\mathbf{M}_{\mathbf{s} 2}=\left[\begin{array}{cc}
m_{2} & 0 \\
0 & m_{3}
\end{array}\right] & \mathbf{C}_{\mathbf{s} \mathbf{2}}=\left[\begin{array}{ll}
c_{22} & c_{23} \\
c_{32} & c_{33}
\end{array}\right] \\
\mathbf{K}_{\mathbf{s} \mathbf{2}}=\left[\begin{array}{ll}
k_{22} & k_{23} \\
k_{32} & k_{33}
\end{array}\right] & \mathbf{B}_{\mathbf{s} \mathbf{2}}=\left[\begin{array}{cc}
-k_{21} & -c_{21} \\
0 & 0
\end{array}\right]
\end{array}
$$

$f_{c}$ is the coupling force between the base and the main structure and $f_{g}$ is the force due to the seismic motion: 


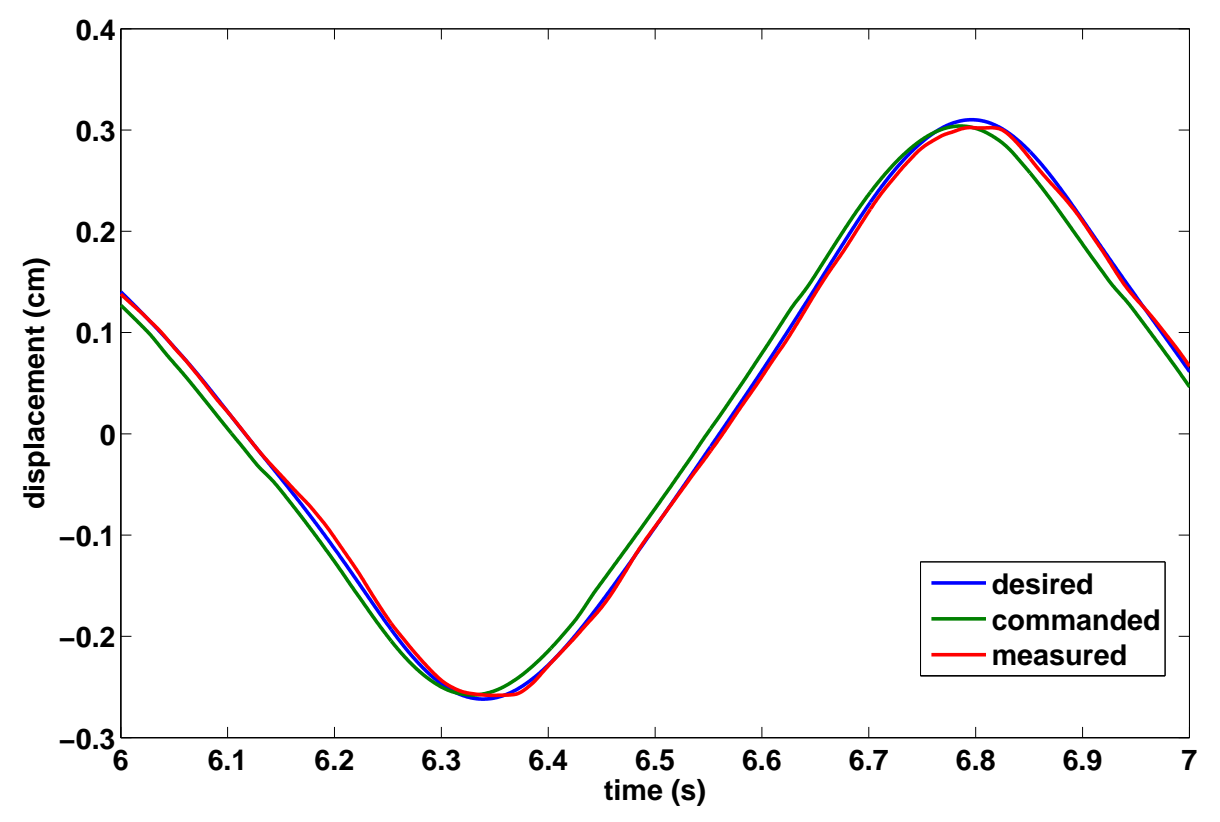

Figure 11: Comparison between the desired, commanded and measured piston displacement.

$$
\begin{aligned}
& f_{c}=c_{12} \dot{x}_{2 a}+k_{12} x_{2 a} \\
& f_{g}=\left(c_{11}+c_{12}\right) \dot{x}_{g}+\left(k_{11}+k_{12}\right) x_{g}
\end{aligned}
$$

The following propositions about the intrinsic stability of the structure will be used in formulating some control laws (Luo et al. 2000):

Proposition 1. The unforced main structure subsystem $S_{m}$ is globally exponentially stable for any bounded initial conditions.

Proposition 2. If the coordinates $(x, \dot{x})$ of the base and the coupling term $\mathbf{B}_{\mathbf{s} 2} \mathbf{x}_{1 \mathbf{a}}$ are uniformly bounded, then the main structure subsystem is stable and the coordinates $(x, \dot{x})$ of the main structure are uniformly bounded for all $t \geq 0$ and any bounded initial conditions.

In this way, the controller is designed for the first floor subsystem assuming that it will stabilize the overall system. Now consider the system of Eqs. ?? and ??. This equation written in relative coordinates becomes:

$$
m_{1} \ddot{x}_{1 r}+c_{11} \dot{x}_{1 r}-c_{12} \dot{x}_{2 r}+k_{11} x_{1 r}-k_{12} x_{2 r}=-f_{m r}-m_{1} \ddot{x}_{g}
$$


Taking the Laplace transform of Eq. 34 yields:

$$
m_{1} s^{2} X_{1 r}(s)+c_{11} s X_{1 r}(s)-c_{12} s X_{2 r}(s)+k_{11} X_{1 r}(s)-k_{12} X_{2 r}(s)=-F_{m r}(s)-m_{1} \ddot{X}_{g}(s)
$$

Rearranging terms from Eq. 35 yields:

$$
X(s)=\frac{1}{m_{1} s^{2}+c_{11} s+k_{11}}\left[-F_{m r}(s)+c_{12} s X_{2 r}(s)+k_{12} X_{2 r}(s)-m_{1} \ddot{X}_{g}(s)\right]
$$

It follows from Figure 1 that the plant $P$ is given by:

$$
P=\frac{1}{m_{1} s^{2}+c_{11} s+k_{11}}
$$

while the perturbation, i.e. the seismic motion is the term $m_{1} \ddot{X}_{g}(s)$. The control input $U_{i}(s)$ is given by:

$$
U_{i}(s)=-F_{m r}(s)+c_{12} s X_{2 r}(s)+k_{12} X_{2 r}(s)
$$

from where the MR damper force can be estimated. The controller design specifications are: $c_{11}=41.36 \pm 5 \%, k_{11}=56720 \pm 5 \%$; the frequencies of interest are the natural frequencies of the system, i.e., $1.09 \mathrm{~Hz}, 3.17 \mathrm{~Hz}$ and $4.74 \mathrm{~Hz}$. The controller performance should achieve the following bounds: robust performance $W_{s 1}=2$ and disturbance rejection $=W_{s 3}=3 \times 10^{-2}$.

Figure 12 - 14 show different stages of the QFT controller design: the templates, the initial loop and the final loop. The final controller is given by:

$$
G(s)=\frac{7802.83(s+499.12)(s+14.72)(s+0.5129)}{(s+6.63)(s+5.324)(s+5.314)}
$$

The control law of Eq. 39 cannot be implemented directly because the force to the MR damper cannot be commanded. Instead, a voltage signal must be sent to the damper to approximately generate the desired force. Two approaches are now considered to determine the voltage to the MR damper that can produce the damping force required to mitigate the vibrations.

The first approach is based on the Clipped Optimal Control algorithm by Dyke et al. (1996). The algorithm is graphically depicted in Figure 16. The dynamics of the MR damper are ignored and the control signal (i.e., the voltage) takes only two values, $0 \mathrm{~V}$ and $5 \mathrm{~V}$, according to the following algorithm:

$$
v=V_{\text {max }} H\left\{\left(f_{m r}-f_{\text {meas }}\right) f_{\text {meas }}\right\}
$$




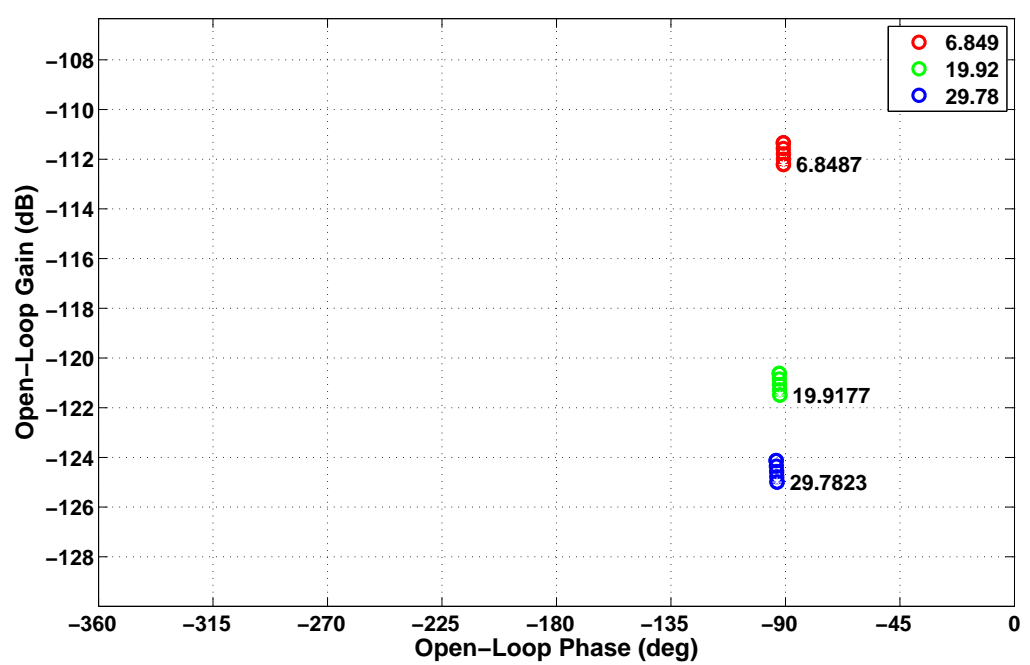

Figure 12: Templates of the system of Eq. 37.

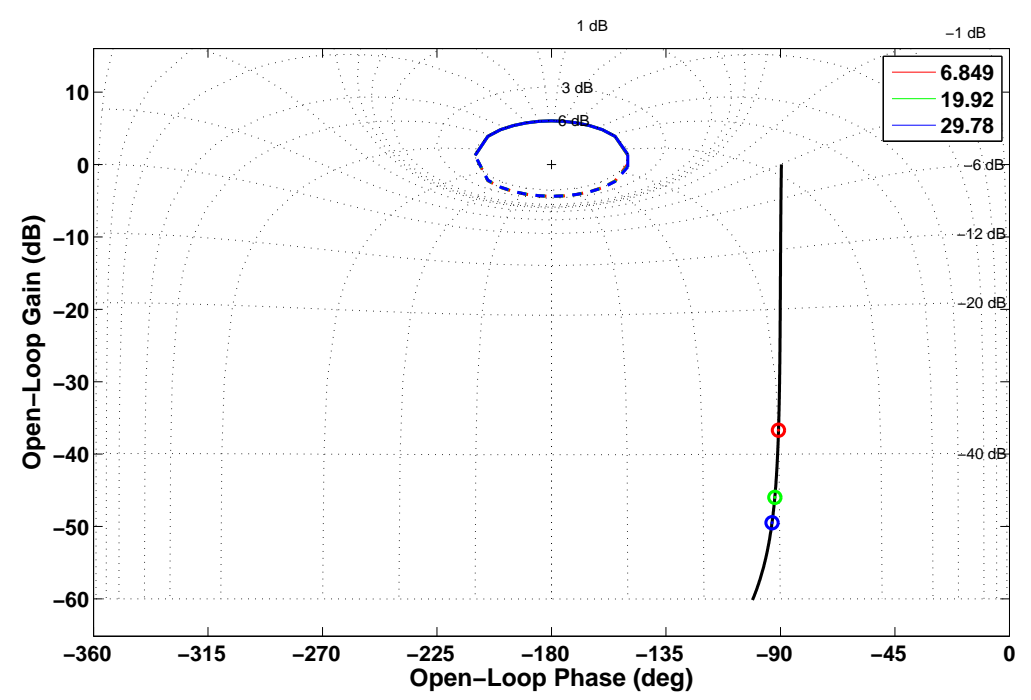

Figure 13: QFT controller initial loop. 


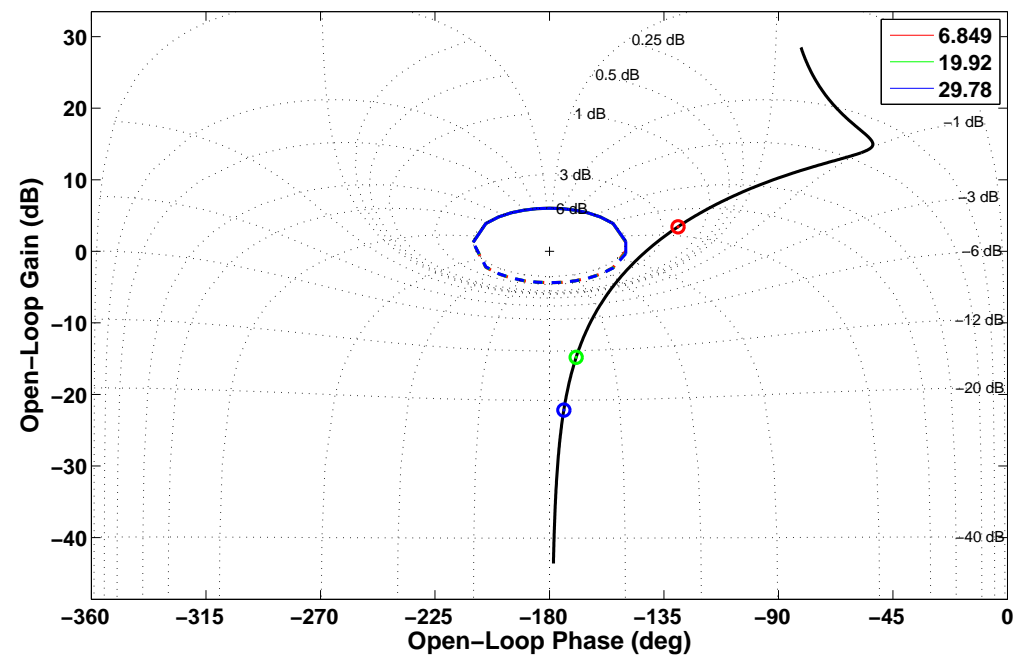

Figure 14: QFT controller final loop.

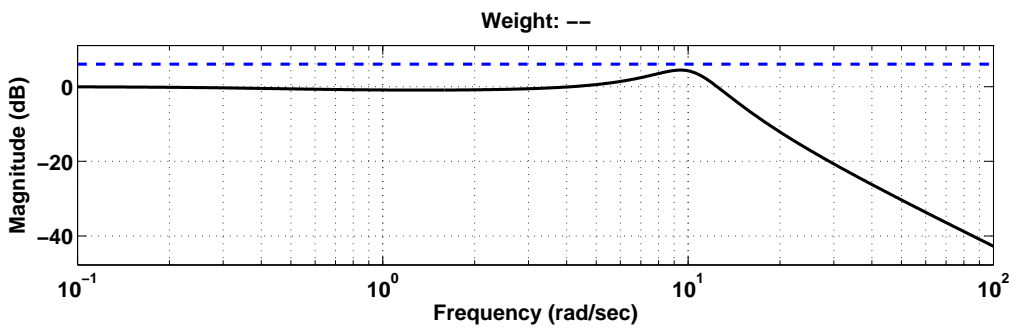

Weight: --

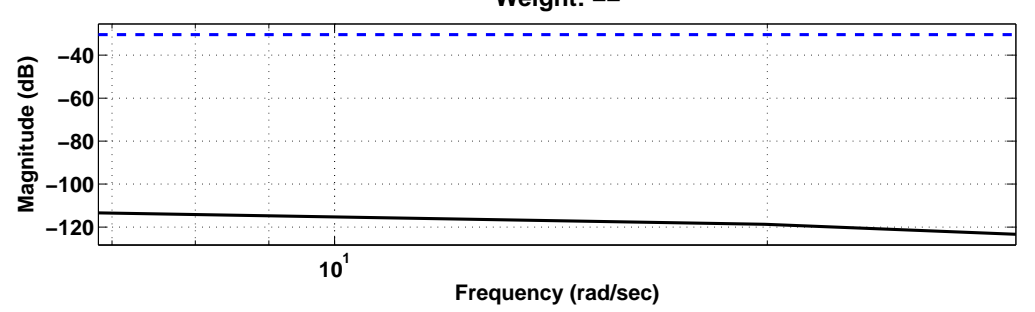

Figure 15: QFT controller robustness analysis. 


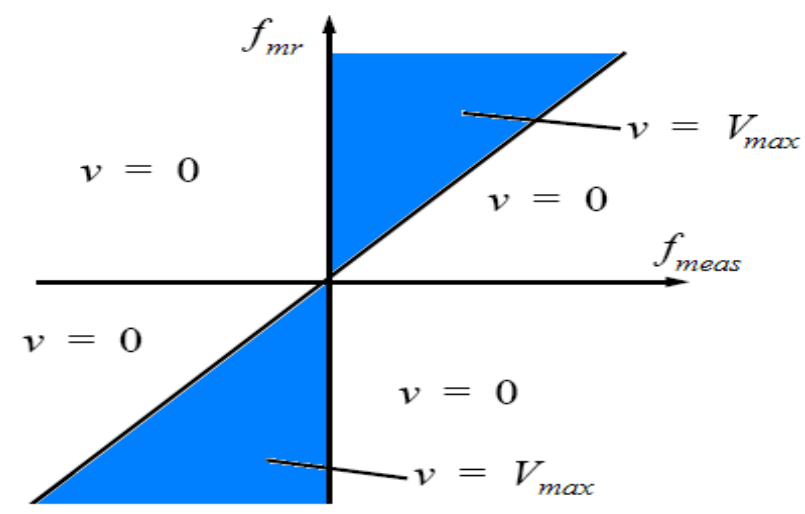

Figure 16: Graphical representation of the Clipped Optimal Algorithm.

where $H\{\cdot\}$ is the Heaviside function, $f_{m r}$ is the force generated by the QFT controller and $f_{\text {meas }}$ is the actual damping force actuating on the system.

The second approach consists of replacing the term $F_{m r}(s)$ with a Laplace representation of the damper dynamics. However, as it has been stated along the paper, the MR damper is a nonlinear device. To solve this problem, it is proposed a representation of the damper as a linear plant with uncertain parameters in such a way that it approximates its dynamics. Consider again the Bouc-Wen model of the MR damper of Eq. 9. It can be divided into to equations: one linear and one nonlinear. Thus:

$$
\begin{aligned}
& f_{\text {lin }}=\left(c_{0 a}+c_{0 b} u_{0}\right) \dot{x}+\left(k_{0 a}+k_{0 b} u_{0}\right) x=a_{1} \dot{x}+a_{2} x \\
& f_{\text {nonlin }}=\left(\alpha_{a}+\alpha_{b} u\right) z_{0}=u_{d} z_{0} \\
& f_{m r}=f_{\text {lin }}+f_{\text {nonlin }} \\
& u_{d}=\left(\alpha_{a}+\alpha_{b} u\right)
\end{aligned}
$$

From Eq. 41, it is observed that the parameters $a_{1}$ and $a_{2}$ vary only with the input voltage. The third parameter, $z_{0}$, is a bounded parameter. See Figure 17. At high velocities, $z$ is approximately constant and thus, $z_{0}$ could take either the maximum or the minimum value depending on the signs of velocity. In this way, Eq. 41 can be seen as a plant with 3 uncertain parameters namely, $a 1, a_{2}$ and $z_{0}$ that describe the dynamics of the damper. In this way, the damper dynamics appear to follow the Bingham model. Figure 18 illustrates this approach with a sinusoidal displacement excitation at 3 levels of voltage.

The representation of the MR damper as an uncertain linear plant can now be incorporated into Eq. 35. The Laplace transform of Eq. 41 yields:

$$
F_{m r}(s)=\frac{a_{1} S_{F}}{S_{L}} s X_{1 r}(s)+\frac{a_{2} S_{F}}{S_{L}} X_{1 r}(s)+S_{F} z_{0} U_{D}(s)
$$




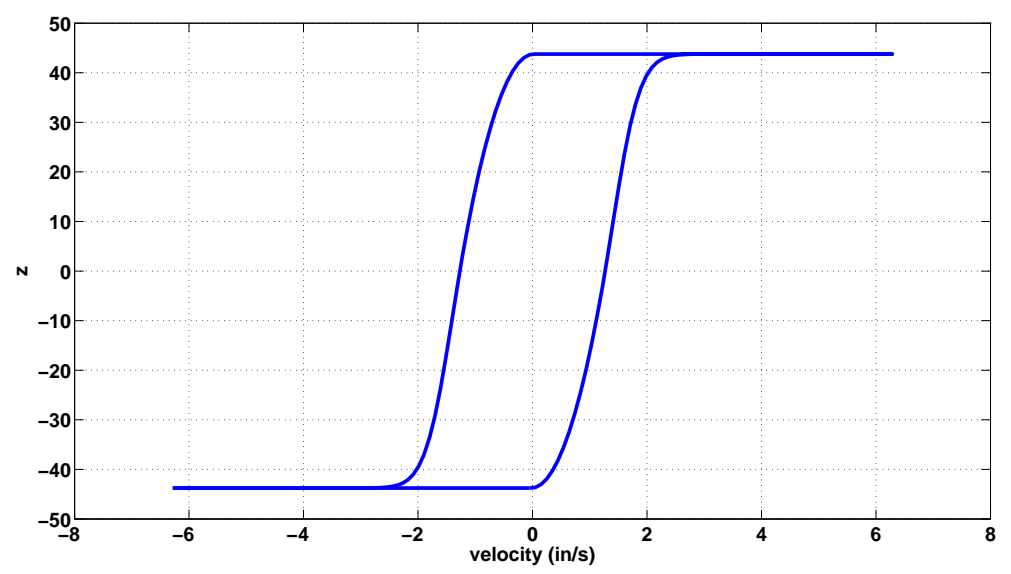

Figure 17: Example of a hysteresis loop.

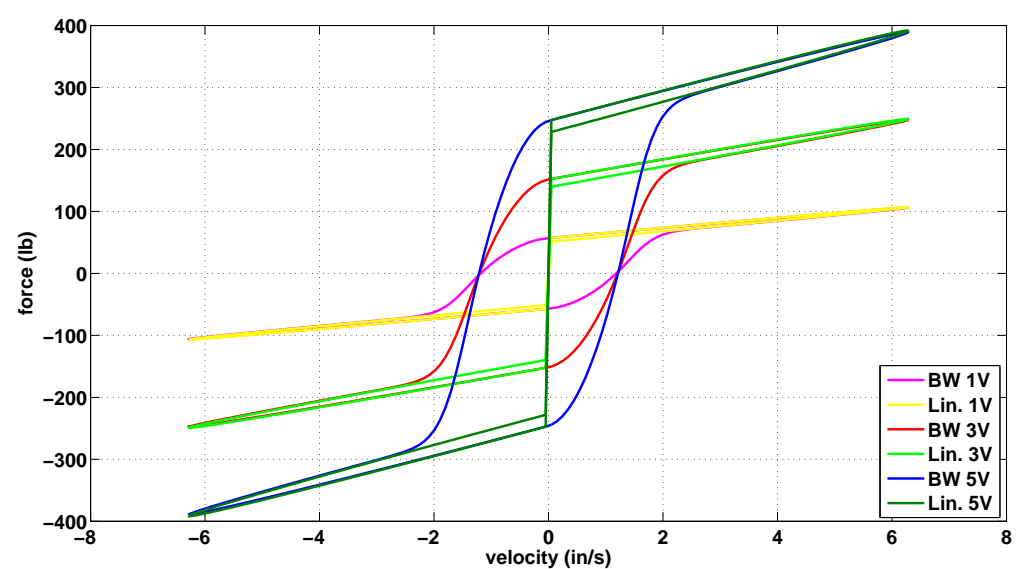

Figure 18: Description of the MR damper as an uncertain plant. 
Substitution of Eq. 46 into Eq. 35 yields:

$X_{1 r}(s)=\frac{S_{F} z_{0}}{m_{1} s^{2}+\left(c_{11}+\frac{a_{1} S_{F}}{S_{L}}\right) s+\left(k_{11}+\frac{a_{2} S_{F}}{S_{L}}\right)}\left[-U_{D}(s)+\frac{\left(c_{12} s X_{2 r}(s)+k_{12} X_{2 r}(s)-m_{1} \ddot{X}_{g}(s)\right)}{S_{F} z_{0}}\right]$

Once again, it follows from Figure 1 that the plant is:

$$
P(s)=\frac{S_{F} z_{0}}{m_{1} s^{2}+\left(c_{11}+a_{1} S_{F} / S_{L}\right) s+\left(k_{11}+a_{2} S_{F} / S_{L}\right)}
$$

and the voltage can be estimated by manipulating the following equation:

$$
U_{i}(s)=-U_{D}(s)+\frac{1}{S_{F} z_{0}}\left(c_{12} s X_{2 r}(s)+k_{12} X_{2 r}(s)\right)
$$

The uncertain parameters and QFT controller specifications are: : $a_{1}=[754.41,4315.06]$, $a_{2}=[1137.57,8355.07]$ and $z_{0}=\{-1.11,1.11\}$. The frequencies of interest are the natural frequencies of the system, i.e., $1.09 \mathrm{~Hz}, 3.17 \mathrm{~Hz}$ and $4.74 \mathrm{~Hz}$. The controller performance should accomplish the following bounds: robust performance $W_{s 1}=2$ and disturbance rejection $=W_{s 3}=3 \times 10^{-2}$.

Figures 19 - 21 show different stages of the controllers design: templates and initial and final loops. The final controller is given by:

$$
G(s)=\frac{67.35\left(s^{2}+5.13 s+59.19\right)\left(s^{2}+0.46 s+212.80\right)}{\left(s^{2}+7.69 s+59.19\right)\left(s^{2}+11.86 s+212.80\right)}
$$

\section{$5 \quad$ Experimental results}

The QFT controllers are now tested in the RTHT setup described previously. The numerical model, i.e. the 3-story building and the controller, are implemented in Matlab/Simulink. The ordinary differential equation solver used is the $4^{\text {th }}$ order Runge-Kutta method with a time step $T_{s}=5 \times 10^{-4}$ seconds. The structure is subject to three different earthquake records, namely, El Centro, Loma Prieta and Northridge as shown in Figure ??; the scale amplitude used is 0.4. Table ?? shows the performance indices used to evaluate the controller performance.

The performance index for the different seismic excitations are shown in Table ??. Figures ?? - ?? show the structure response and the MR damper performance when subject to the El Centro seismic excitation. Figures ?? and ?? show the performance of the MR damper (the actual damper, i.e. not scaled), and particularly, a comparison of the dynamics predicted by the Bouc-Wen model and that obtained experimentally. 


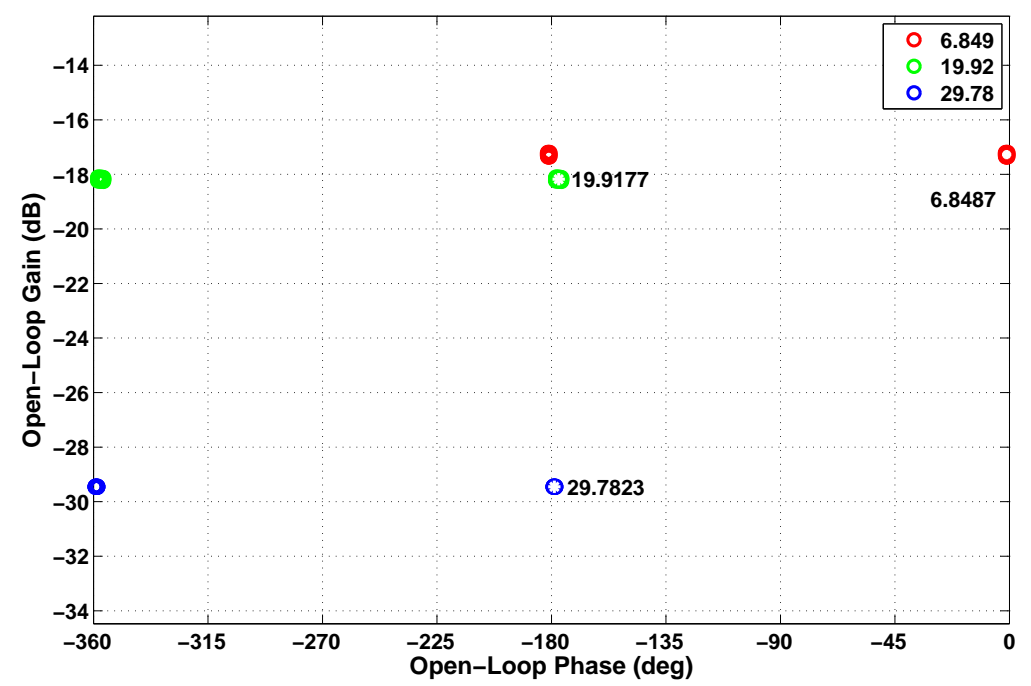

Figure 19: Templates of the system of Eq. 48.

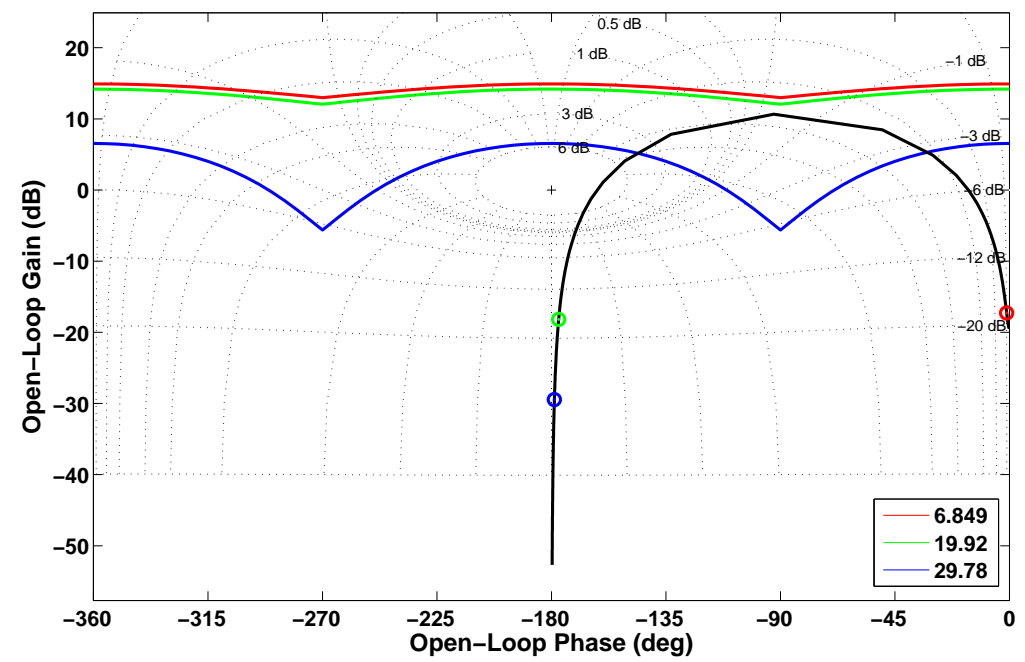

Figure 20: QFT controller initial loop. 


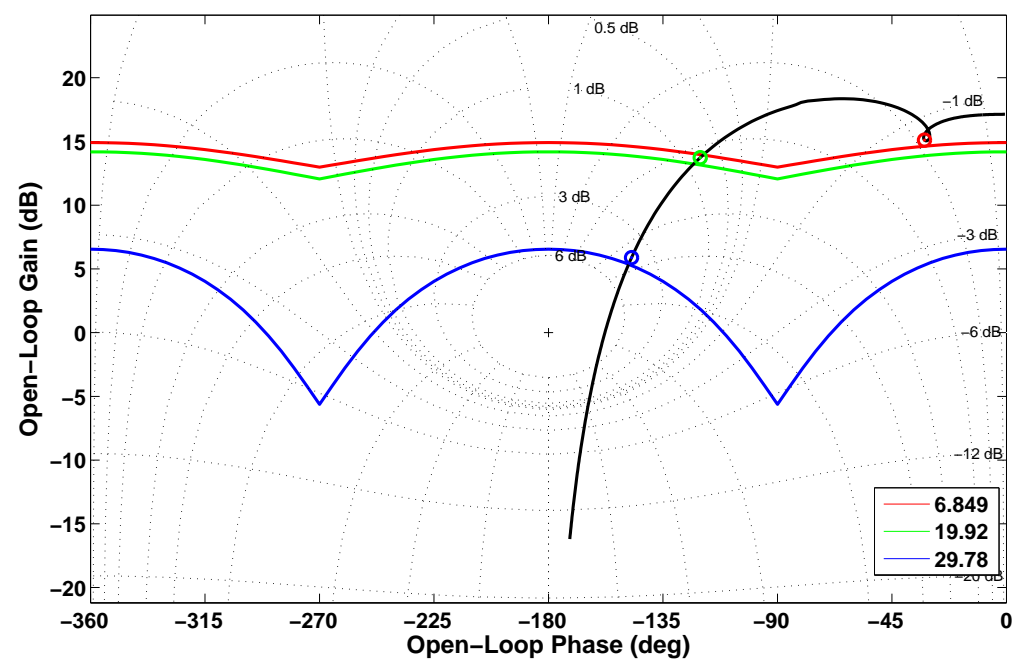

Figure 21: QFT controller final loop.
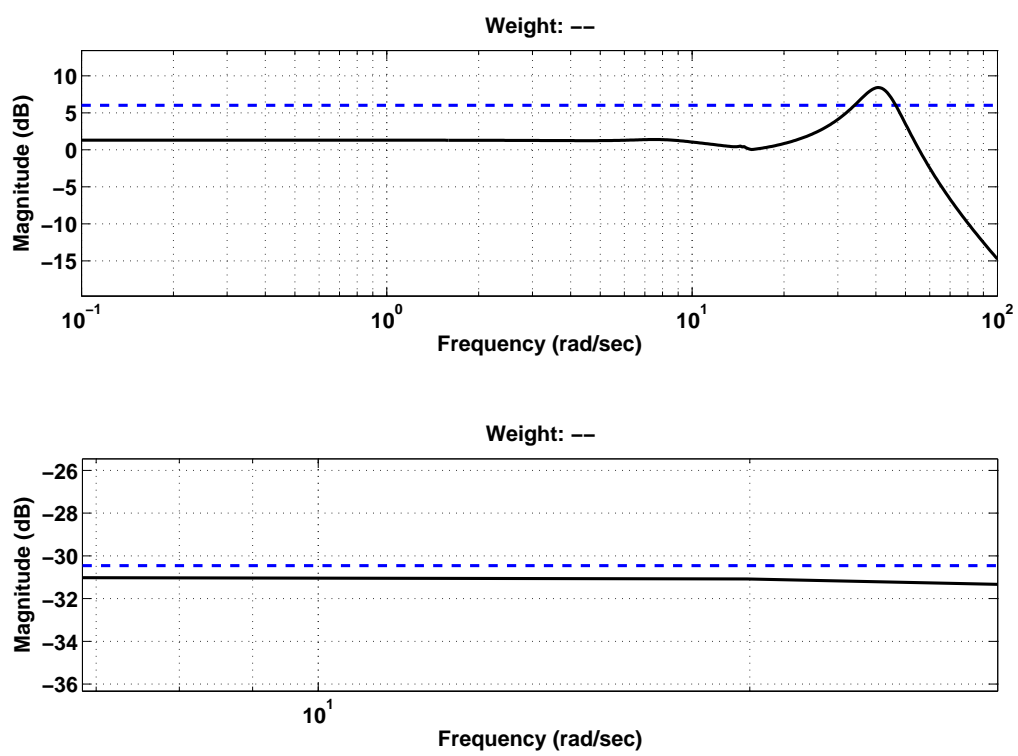

Figure 22: QFT controller robustness analysis. 


\begin{tabular}{cc}
\hline \hline Index & Description \\
\hline$J_{1}=\max _{i, t}\left(\frac{\left|\ddot{x}_{a i}(t)\right|}{\ddot{x}_{a}^{\text {max }}(t)}\right)$ & Normalized peak floor acceleration. \\
$J_{2}=\max _{i, t}\left(\frac{\left\|\ddot{x}_{a i}(t)\right\|}{\left\|\ddot{x}_{a}^{m a x}\right\|}\right)$ & Normed peak acceleration \\
$J_{3}=\max \left(\left|x_{1 r}(t)\right|\right)$ & $1^{s t}$ floor peak relative displacement under control. \\
$J_{4}=\max _{\left(\left|\ddot{x}_{1 a}(t)\right|\right)} 1^{\text {st }}$ floor peak absolute acceleration under control. \\
$J_{5}=\max _{t, i}\left(\frac{\left|f_{m r d}(t)\right|}{W}\right)$ & Maximum control force. \\
$J_{6}=\left(\frac{1}{\tau} \int_{0}^{\tau}\left[\dot{x}_{m}(t)\right]^{2} d t\right)^{1 / 2}$ & RMS control power. \\
\hline
\end{tabular}

Table 1: Performance indices.
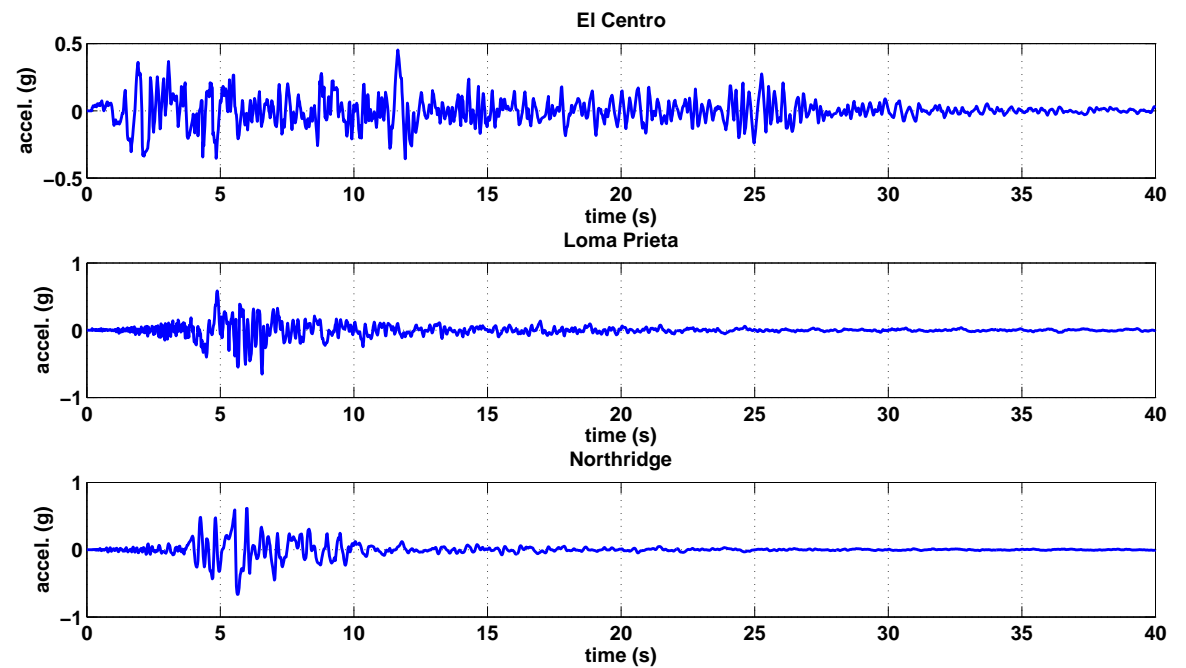

Figure 23: Records of El Centro, Loma Prieta and Northridge earthquakes.

Performance indices $J_{1}-J_{4}$ show that both controllers have a similar performance and in most of cases, the QFT controllers based on the MR damper dynamics is better than the other. However, performance indices $J_{5}$ and $J_{6}$ show that for this controller to perform better in reducing the structure response, it makes use of a greater control effort. According to the performance indices and the structure response, the control objectives were satisfactorily accomplished, i.e. a reduction in displacement and acceleration response was achieved with both QFT controllers.

\section{Conclusions}

In this paper, a new semiactive controller based on the Quantitative Feedback Theory method has been proposed to reduce the vibrations in a 3-story building equipped with 

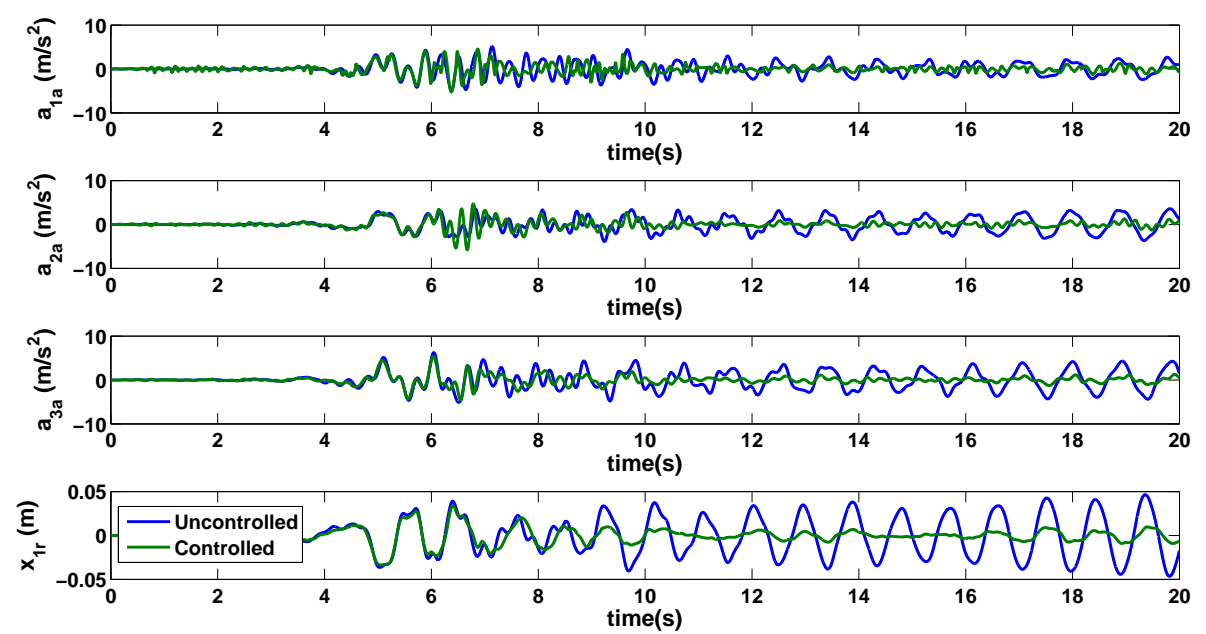

Figure 24: Clipped QFT: Structure response under Loma Prieta earthquake.
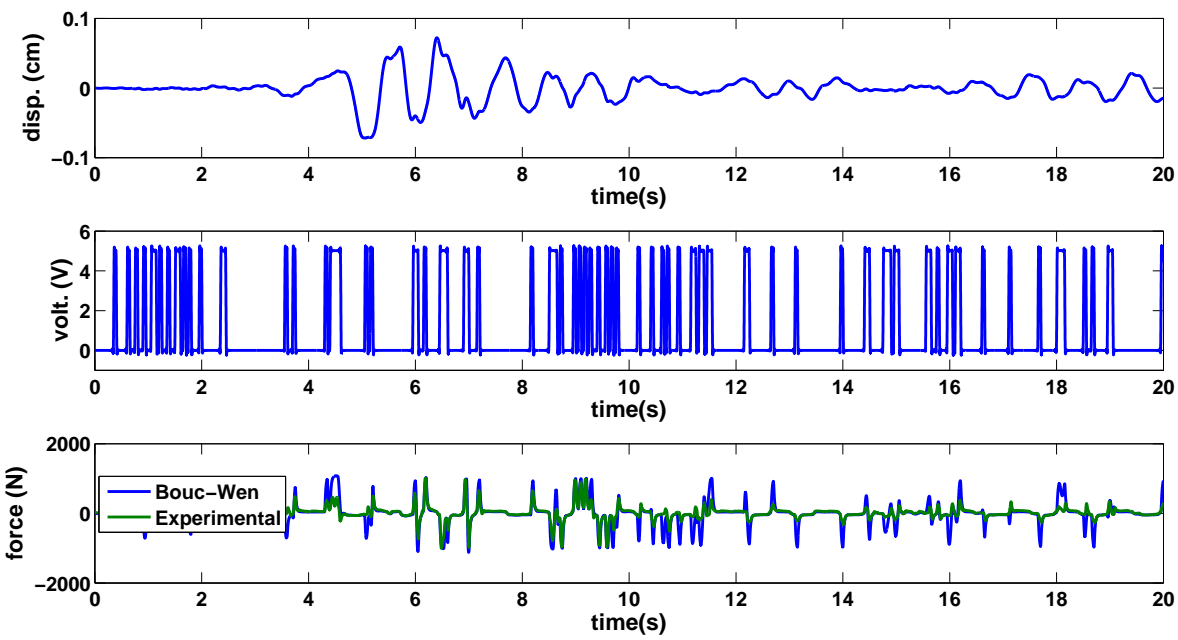

Figure 25: Clipped QFT: MR damper response under Loma Prieta earthquake. 

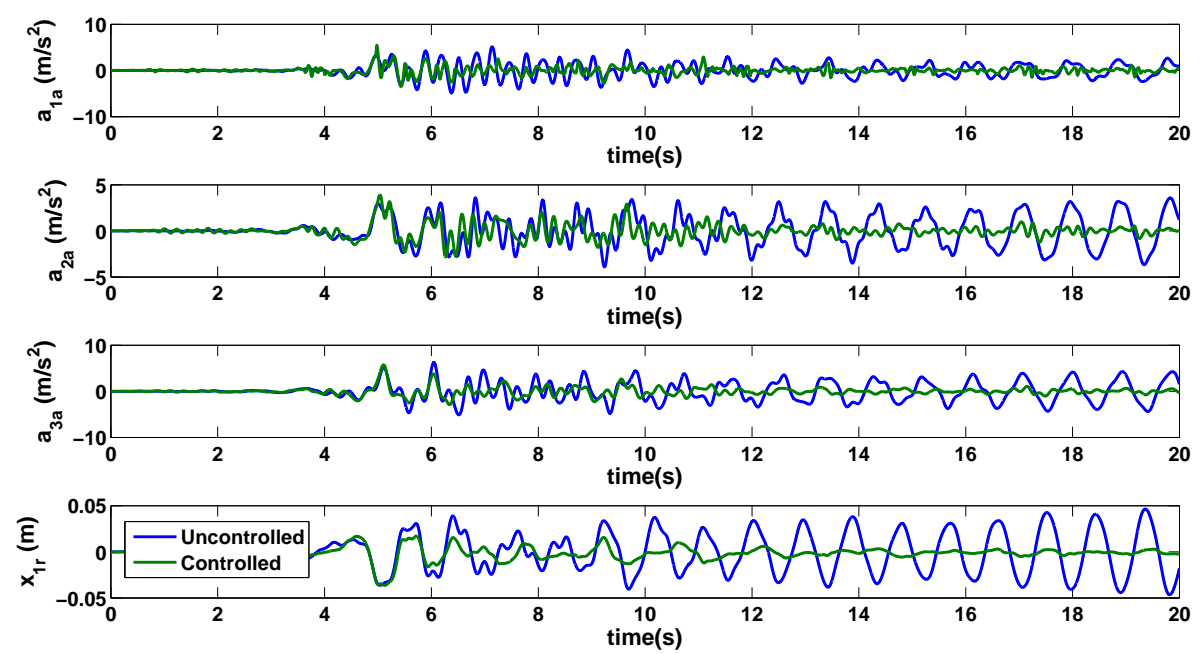

Figure 26: Model based QFT: Structure response under Loma Prieta earthquake.
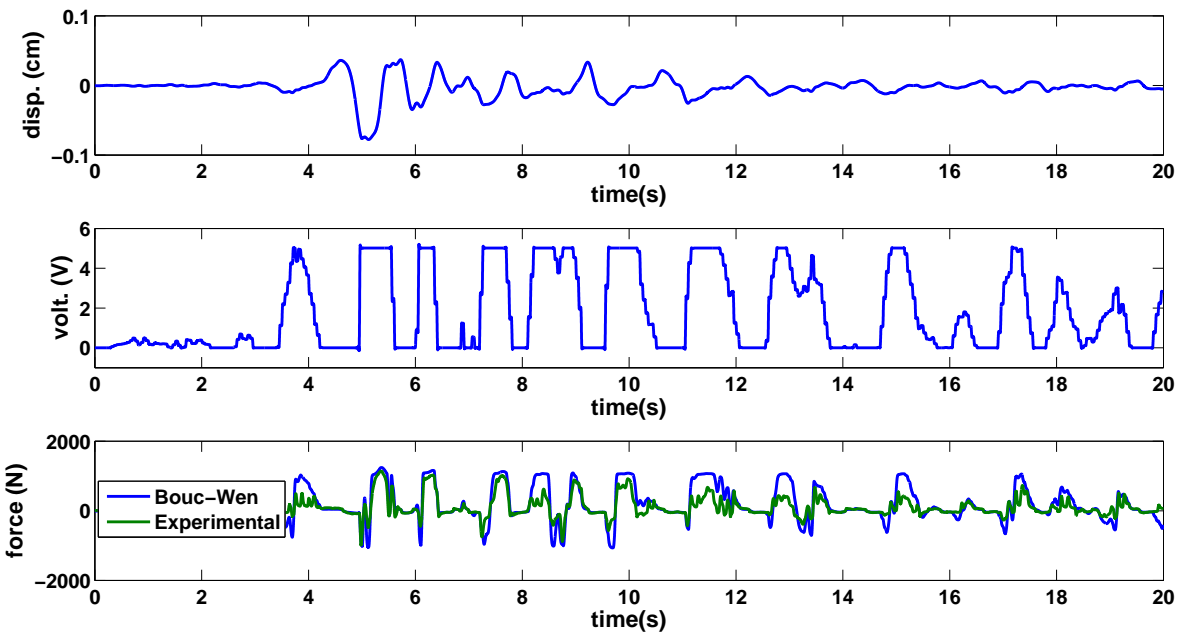

Figure 27: Model based QFT: MR damper response under Loma Prieta earthquake. 


\begin{tabular}{cccccccc}
\hline \hline Earthquake & Controller & $\boldsymbol{J}_{\mathbf{1}}$ & $\boldsymbol{J}_{\mathbf{2}}$ & $\boldsymbol{J}_{\mathbf{3}}(\mathbf{c m})$ & $\boldsymbol{J}_{\mathbf{4}}\left(\mathbf{m} / \mathbf{s}^{\mathbf{2}}\right)$ & $\boldsymbol{J}_{\mathbf{5}}$ & $\boldsymbol{J}_{\mathbf{6}}(\mathbf{N})$ \\
\hline \multirow{2}{*}{ El Centro } & Clipped QFT & 0.67 & 0.40 & 3.36 & 3.77 & 0.12 & 259.64 \\
& Model based QFT & 0.62 & 0.30 & 2.31 & 3.92 & 0.11 & 346.05 \\
Loma Prieta & Clipped QFT & 0.92 & 0.47 & 3.38 & 5.25 & 0.11 & 178.04 \\
& Model based QFT & 0.92 & 0.41 & 3.64 & 5.47 & 0.11 & 283.86 \\
Northridge & Clipped QFT & 0.73 & 0.52 & 6.27 & 5.94 & 0.11 & 202.37 \\
& Model based QFT & 0.64 & 0.42 & 4.76 & 5.06 & 0.11 & 302.42 \\
\hline
\end{tabular}

Table 2: Controller performance indices under El Centro, Loma Prieta and Northridge earthquakes.

an MR damper. Two variations were presented: one based on a modification of the clipped optimal algorithm and another one based on the nonlinear dynamics of the MR damper. The controllers were experimentally tested in a real-time hybrid testing setup. Both controllers successfully achieved the proposed goal of reducing the structure response when subject to a seismic motion.

\section{Acknowledgements}

This work has been partially funded by the European Union (European Regional Development Fund) and the Commission of Science and Technology of Spain (CICYT) through the coordinated research projects DPI-2005-08668-C03 and by the government of Catalonia through SGR00296. M. Zapateiro acknowledges the FI and BE Grants of the Department for Innovation, University and Enterprise of the Government of Catalonia (Spain). H.R. Karimi acknowledges the Juan de la Cierva fellowship from the Spanish Ministry of Science and Education.

\section{References}

Carrion, J. \& Spencer, B. (2007), Model-based strategies for real-time hybrid testing, Technical report, University of Illinois at Urbana-Champaign.

Dyke, S., Jr., B. S., Sain, M. \& Carlson, J. (1998), 'An experimental study of MR dampers for seismic protection', Smart materials and structures 7, 693-703.

Dyke, S., Spencer, B., Sain, M. \& Carlson, J. (1996), 'Modeling and control of magnetorheological dampers for seismic response reduction', Smart Materials and Structures $5,565-575$.

Houpis, C., Rasmussen, S. \& García-Sanz, M. (2005), Quantitative Feedback Theory: Fundamentasl and Applications., CRC Press, USA. 
Jansen, L. \& Dyke, S. (2000), 'Semiactive control strategies for MR dampers: comparative study', Journal of Engineering Mechanics 126, 795-803.

Kim, H. \& Roschke, P. (2006), 'Fuzzy control of base-isolation system using multiobjective genetic algorithm', Computer-Aided Civil and Infrastructure Engineering 21, 436-446.

Luo, N., Rodellar, J., la Sen, M. D. \& Vehí, J. (2000), 'Output feedback sliding mode control of base isolated structures', Journal of the Franklin Institute 337, 555-577.

Luo, N., Rodellar, J. \& Villamizar, R. (2003), Robust control law for a friction-based semiactive controller of a two-span bridge, in 'Proc. SPIE $10^{\text {th }}$ Annual International Symposium on Smart Structures and Materials', San Diego, California, U.S.A.

Luo, N., Villamizar, R. \& Vehi, J. (2007), Backstepping control of nonlinear building structures with hysteretic and frictional dynamics, in 'European Control Conference', Kos, Greece.

Luo, N., Villamizar, R. \& Vehi, J. (n.d.), Quantitative feedback thoery (QFT): application to structural control, in 'China-Japan-US symposium on Health Monitoring and Control of Structures', Dalian, China.

McClamroch, N. \& Gavin, H. (1995), Closed loop structural control using electrorheological dampers, in 'Proceedings of the American Control Conference', Seattle, Washington, U.S.A.

McClamroch, N., Gavin, H., Ortiz, D. \& Hanson, R. (1994), Electrorheological dampers and semi-active structural control, in 'Proceedings of the $33^{\text {rd }}$ Conference on Decision and Control'.

Moon, S., Bergman, L. \& Voulgaris, P. (2003), 'Sliding mode control of cable-stayed bridge subjected to seismic excitation', Journal of Engineering Mechanics 129, 71-78.

Nagarajaiah, S., Narasimhan, S., Agrawal, A. \& Tang, P. (2006), Semiactive Lyapunov controller for phase II seismic isolated bridge benchmark, in 'Structures Congress 2006', St. Louis, Missouri, U.S.A.

Park, C. \& Jeon, D. (2002), 'Semiactive vibration control of a smart seat with an MR fluid damper considering its time delay', Journal of Intelligent Material Systems and Structures 13, 521-524.

Schurter, K. \& Roschke, P. (2001), 'Neuro-fuzzy control of structures using acceleration feedback', Smart Materials and Structures 10, 770-779.

Spencer, B., Dyke, S., Sain, M. \& Carlson, J. (1997), 'Phenomenological model of a magnetorheological damper', ASCE Journal of Engineering Mechanics 123, 230-238.

Spencer, B. \& Sain, M. (1997), 'Controlling buildings: a new frontier in feedback', IEEE Control Systems Magazine 17, 19-35. 
Spencer, B. \& Song., T. (1999), New applications and development of active, semi-active and hybrid control techniques for seismic and non-seismic vibration in the USA, in 'Proceedings of International Post-SMIRT Conference Seminar on Seismic Isolation, Passive Energy Dissipation and Active Control of Vibration of Structures', Cheju, Korea.

Villamizar, R. (2005), Robust control of systems subjected to uncertain disturbances and actuator dynamics, PhD thesis, University of Girona.

Villamizar, R., Luo, N., Vehi, J. \& Rodellar, J. (2003), Semiactive sliding mode control of uncertain base isolated structures with actuator dynamics, in 'Proc. SPIE $10^{\text {th }}$ Annual International Symposium on Smart Structures and Materials', Warsaw, Poland.

Wang, X. \& Gordaninejad, F. (2002), 'Lyapunov-based control of a bridge using magnetorheological fluid dampers', Journal of Intelligent Material Systems and Structures 13, 415-419.

Yang, G. (2001), Large-scale magnetorheological fluid damper for vibration mitigation: modeling, testing and control, PhD thesis, University of Notre Dame.

Yoshioka, H., Ramallo, J. \& Spencer, B. (2002), "Smart” based isolation strategies employing magnetorheological dampers', Journal of engineering mechanics 128, 540551 .

Zapateiro, M., Karimi, H. \& Luo, N. (2008), Qft control for vibration reduction in structures equipped with $\mathrm{mr}$ dampers, in 'American Control Conference', Seattle, U.S.A.

Zapateiro, M., Villamizar, R. \& Luo, N. (2008), 'Semiactive seismic vibration control of structures equipped with magnetorheological dampers', International Journal of Factory Automation, Robotics and Soft Computing. 